\title{
COMPARISON OF EFFECTIVENESS OF INTRAARTICULAR INJECTIONS OF HYALURONIC ACID AND CORTICOSTEROIDS IN THE TREATMENT OF PATIENTS WITH KNEE OSTEOARTHRITIS SYMPTOMS
}

\author{
Syed Haider Tirmizi, Amer Fakhr, Ahmed Amer*, Rizwan Yusuf**, Kaswar Sajjad, Shah Muhammad Khan*** \\ Pak Emirates Military Hospital/National University of Medical Sciences (NUMS) Rawalpindi Pakistan, *Foundation University Medical College, Islamabad \\ Pakistan, ${ }^{* *}$ Combined Military Hospital Okara/National University of Medical Sciences (NUMS) Pakistan, ${ }^{* * *}$ Bacha Khan Medical College, Mardan Pakistan
}

\section{ABSTRACT}

Objective: To compare the effectiveness of intraarticular injections of hyaluronic acid and corticosteroids in the treatment of patients with knee osteoarthritis symptoms.

Study Design: Prospective comparative study.

Place and Duration of Study: Rheumatology/General Medicine department, Pak Emirates Military Hospital Rawalpindi, from May 2019 to Jun 2020.

Methodology: Patient of knee osteoarthritis with active symptoms of pain and stiffness who fulfilled American college of rheumatology criteria of 1997 were included in the study. They were randomly divided into two groups with group A receiving intraarticular hyaluronic acid. Western Ontario and McMaster Universities Osteoarthritis Index (WOMAC) was administered before and three months after the management to assess the efficacy of treatment in both the groups. Student ttest was applied to ascertain that the difference in the WOMAC scores before and after the management has been statistically significantly different in both groups.

Results: A total of 150 patients of osteoarthritis of knee joint were included in the study. Mean age of the study participants was $58.439 \pm 7.35 .85(56.7 \%)$ patients were female while $65(43.3 \%)$ were male. $81(54 \%)$ received the intraarticular hyaluronic Acid while $69(46 \%)$ received the intraarticular steroids. Mean difference before and after the management in WOMAC score in corticosteroids group was $9.295 \pm 1.24$ while in hyaluronic Acid group was $5.41 \pm 4.556$ ( $p$-value $<0.01$ ).

Conclusion: Both hyaluronic Acid and corticosteroids were effective to reduce the symptoms of osteoarthritis knee in our target population, but intraarticular steroids emerged as the better option from the two in terms of efficacy for knee osteoarthritis.

Keywords: Corticosteroids, Efficacy, Hyaluronic acid, Knees, Osteoarthritis.

This is an Open Access article distributed under the terms of the Creative Commons Attribution License (https://creativecommons.org/licenses/by-nc/4.0/), which permits unrestricted use, distribution, and reproduction in any medium, provided the original work is properly cited.

\section{INTRODUCTION}

Pain has been one of the most common symptoms with which patients present to the health care stings all around the world ${ }^{1}$. Joints have been common site of pain and stiffness leading to poor health related quality of life in a large number of patients ${ }^{2}$. Knee has been one of the commonly affected jointed in this regard due to number of reasons ${ }^{3}$. Osteoarthritis of knee has been frequently diagnosed condition globally and has been on a rise due to longevity and may be increased prevalence of obesity and other metabolic disorders 4 .

Osteoarthritic changes in knee may lead to multiple symptoms including pain, swelling, stiffness, reduced range of motion etc. Multiple local and systemic treatment options have been used to control the symptoms until patient has been offered the definitive management. Use of NSAIDs, local and systemic steroids and local and systemic hyaluronic acid have been few

Correspondence: Dr Syed Haider Tirmizi, Resident Medicine, Pak Emirates Military Hospital, Rawalpindi Pakistan

Received: 28 Jun 2020; revised received: 07 Sep 2020; accepted: 18 Sep 2020 of the commonly used management options by rheumatologists, pain experts or orthopedic surgeons till the patient gets the total knee replacement ${ }^{5,6}$.

Multiple randomized and non-randomized trials and reviews have been published in past few years to find the best management for the symptomatic relief of the patients suffering from osteoarthritis of knee joint which has a pivotal role in weight bearing and walking. Leopold et al, performed a randomized control trial comparing the efficacy of corticosteroids with hyaluronic acid. They concluded that after six months of management both treatments were equally effective in control of pain symptomatology among patients with knee osteoarthritis. Interesting findings they generated were that male patients were overall less responsive to treatment as compared to female patients7. Tammachote et al, compared intraarticular single-shot Hylan GF20 hyaluronic acid injection with intraarticular corticosteroid injection ad came up with the findings that both the treatment options were equally effective for management of all the symptoms of osteoarthritis of knee joint. Pain was responded early in the first week 
while stiffness followed that in second week in terms of response ${ }^{8}$. Smith et al, published a paper by moving a step ahead of previous studies and compared combined intra-articular injection of corticosteroid and hyaluronic acid with hyaluronic acid alone. Their findings were that at the end of 24 and 52 weeks combination treatment was better in controlling pain symptoms related to osteoarthritis of knee joint as compared to intraarticular use of hyaluronic acid alone 9 .

Definitive management of knee osteoarthritis has been total knee replacement which is still not possible for all the patients especially in our part of the world where multiple factors including the cost deprive a large number of people from even the basic treatment. Symptomatic treatment carries a huge importance in this regard and suitable options from efficacy, tolerability and cost effectiveness point of view should be used in routine. Ayaz et al, published a survey done on local population that still a huge chunk of population has been using complementary therapies for knee osteoarthritis in Pakistan ${ }^{10}$. We therefore planned this study to fill the existing gap in literature for the local population with rationale to compare the effectiveness of intraarticular injections of hyaluronic acid and corticosteroids in the treatment of patients with knee osteoarthritis symptoms presenting at rheumatology/ medicine department of Pak Emirates Military Hospital, Rawalpindi.

\section{METHODOLOGY}

This prospective comparative study was conducted from May 2019 to March 2020 patients on presenting at General Medicine/Rheumatology Outpatient department of Pak Emirtes Military Hospital Rawalpindi who fulfilled the American College of Rheumatology classification criteria of active osteoarthritis ${ }^{11}$, of knee with age between 18 and 60 years. Sample size was calculated by using the WHO sample size calculator and keeping the population prevalence proportion of response to treatment in Osteoarthritis at $5.2 \%^{12}$. Non probability consecutive sampling technique was used to gather the required sample size for this study and then lottery method was used to randomly divide the patients into two groups for the purpose of treatment. Patients with causes of knee pain other than osteoarthritis were excluded from the study. Patients with recent fractures or limb surgeries or those having any vitamin or calcium deficiency or any other metabolic or neoplastic abnormalities causing bone pains were excluded from the study. Patients with history of allergic reactions to any of the medications un- der study were also not included in the study. Patients taking any complementary therapies or those who cold not be followed up for three months duration were also excluded from the study.

Permission from hospital ethics committee via letter number $\mathrm{A} / 28 / \mathrm{EC} / 142 / 20$ was sought prior to commencement of study. All the patients signed the informed consent form after full description of the study and adverse effects of medications and intraarticular procedure before getting enrolled into the study. Patients were divided into two groups randomly via lottery method. Group A received the intraarticular corticosteroid (methylprednisolone $80 \mathrm{mg}$ ) while group $B$ received the intra articular hyaluronic acid AS weekly injection of $32 \mathrm{mg} / 2 \mathrm{~mL}$ for 3 weeks ${ }^{13,14}$.

Response of the patients was assessed on the Western Ontario and McMaster Universities Osteoarthritis Index (WOMAC). It has three domains of pain, stiffness and physical functioning covering all the main aspects of osteoarthritis. Twenty-four items cover all these three domains in the patients suffering from osteoarthritis. Score can range from 0-100 depending upon the sum of all the responses by the patients ${ }^{15}$. WOMAC was administered to the patients in both the groups before starting the treatment and then three months after the designated treatment. Difference in score on WOMAC was compared before and after the treatment in both groups.

Statistical analysis was performed by using the SPSS 23. Frequency and percentage were calculated for the qualitative variables in the study including gender and the type of treatment option used after randomization of the patients. Mean and standard deviation was calculated for the age of the patients, difference in the WOMAC scores before and after the management and duration of illness. Student t-test was applied to ascertain that the difference in the WOMAC scores before and after the management has been statistically significantly different in both groups or not and $p$-value $\leq 0.05$ was used for that purpose.

\section{RESULTS}

A total of 150 patients of osteoarthritis knee were included in the study. Table-I showing that mean age of the study participants was $58.439 \pm 7.35$. Out of 85 $(56.7 \%)$ patients were female while $65(43.3 \%)$ were male. Mean duration of symptoms before they underwent intraarticular management was $14.1 \pm 3.455$ months. Out of 150 patients randomly assigned to both forms of treatment, $81(54 \%)$ received the intraarticular hyaluronic Acid while 69 (46\%) received the intraarti- 
cular steroids. Table-II concludes that mean difference before and after the management in WOMAC score in corticosteroids group was $9.295 \pm 1.24$ while in hyaluronic acid group was $5.41 \pm 4.556$ ( $p$-value $<0.01$ ).

Table-I: Characteristics of patients with osteoarthritis knee included in the study $(n=150)$.

\begin{tabular}{|c|c|}
\hline Variables & Values \\
\hline \multicolumn{2}{|l|}{ Age (years) } \\
\hline Mean \pm SD & $58.439 \pm 7.35$ \\
\hline Range (min-max) & 18-57years \\
\hline Mean duration of Symptoms (months) & $14.1 \pm 3.455$ \\
\hline \multicolumn{2}{|l|}{ Gender } \\
\hline Male & $65(43.3 \%)$ \\
\hline Female & $85(56.7 \%)$ \\
\hline \multicolumn{2}{|l|}{ Treatment Response } \\
\hline $\begin{array}{l}\text { Mean change in WOMAC score in } \\
\text { steroid group }\end{array}$ & $9.295 \pm 1.24$ \\
\hline Mean change in WOMAC score in & \\
\hline Hyaluronic Acid group & $5.41 \pm 4.556$ \\
\hline \multicolumn{2}{|l|}{ Treatment Options } \\
\hline Hyaluronic Acid group & $81(54 \%)$ \\
\hline Corticosteroid group & $69(46 \%)$ \\
\hline
\end{tabular}

Table-II: Difference in western ontario and mcmaster universities osteoarthritis Index score in both the groups before and after the treatment.

\begin{tabular}{l|c|c|c}
\hline Groups & $\begin{array}{c}\text { Cortico } \\
\text {-steroid }\end{array}$ & $\begin{array}{c}\text { Hyaluronic } \\
\text { Acid }\end{array}$ & $\begin{array}{c}p \text { - } \\
\text { value }\end{array}$ \\
\hline Number of patients & 69 & 81 & \\
\hline $\begin{array}{l}\text { Difference in Western } \\
\text { Ontario and McMaster }\end{array}$ & $9.295 \pm$ & $5.41 \pm 4.556$ & $<0.001$ \\
$\begin{array}{l}\text { Universities } \\
\text { osteoarthritis index } \\
\text { score }\end{array}$ & 1.24 & & \\
\hline
\end{tabular}

\section{DISCUSSION}

Patients coming to hospitals usually more concerned to get relieved from the pain they have been suffering. Especially when they reach to a tertiary care setting, already a lot of time has passed and they have been living with their symptoms so their expectations really go high with the tertiary care physicians to manage their pain effectively as soon as possible. Leading cause of knee pain all around the globe has been osteoarthritis for which now there is a definitive management plan as well2,4. There has been a long waiting list for total knee replacement in the developed countries and in developing country like ours very less people undergo definitive management due to multiple problems so symptomatic treatment holds a vital position in management of osteoarthritis of knee joint. We therefore planned this study with the rationale to compare the effectiveness of intraarticular injections of hyaluro- nic acid and corticosteroids in the treatment of patients with knee osteoarthritis symptoms.

Abedi et $a l^{16}$, conducted a very similar study in a hospital in our neighboring country Iran and concluded that both treatment options were efficacious in managing different features of osteoarthritis of knee joint. Corticosteroids were more effective in cute management of pain while hyaluronic acid was more effective to treat the symptoms related to stiffness of the joint ${ }^{16}$. We did not study the individual symptoms or domains of the WOMAC but focused on the reduction in total score and through that found that intraarticular corticosteroids have been more effective after three months of the treatment.

Ran et al, conducted a detailed metanalysis to compare the role of intraarticular corticosteroids and hyaluronic acid for management of pain and mobility symptoms related to osteoarthritis of knee. They included 5 RCTs with over one thousand patients and concluded that both the treatment options were efficacious for patients with osteoarthritis of knee joint. Methylprednisolone was more effective in terms of pain reduction as compared to hyaluronic acid. Long term follow up did not show any significant difference in the adverse effects ${ }^{17}$. We did not study the adverse effects but in terms of efficacy our results supported the results of metanalysis of Ran et al.

Yaftali et al, concluded that osteoarthritis has been a common condition that affects many individuals resulting in pain, reduced mobility, and decreased function. Corticosteroids have been a mainstay of osteoarthritis treatment. They provide short-term pain improvement and can be used for osteoarthritis flares. Hyaluronic acid injections have also been proved as effective treatment options for patients with osteoarthritis of knee. Despite some debate between societies, a large number of recent studies have shown hyaluronic acid to be a viable treatment option showing longerterm improvement in both pain and function ${ }^{18}$. Our results reflected that both treatment options have been effective for symptoms of osteoarthritis of knee but corticosteroids have been more effective in this regard.

Tammachote et al, concluded that triamcinolone acetonide provided similar improvement in knee pain, function, and range of motion compared with hylan GF20 at the 6-month follow-up, with better pain control in the first week and better knee functional improvement in the second week ${ }^{8}$. We did not follow up the patients each week and used prednisolone as treatment option for the corticosteroid group and observed a 
statistically significant difference between efficacy of corticosteroids and hyaluronic acid. Corticosteroids were clearly superior to hyaluronic acid in terms of efficacy on WOMAC index.

Sample size was too small, and it was a single center study. Though comorbid conditions clearly related to bone pains and affecting treatment response were excluded but still other medical conditions were not controlled. Randomization as the only measure which could minimize this bias from our study. Patients were only checked for response after 3 months. Weekly follow up and long term follow up as well as osteoarthritis of knee is a chronic non resolving condition would have generated better results in this regard. Future studies with better design preferably triple blind randomized controlled trials may generate generalizable results.

\section{CONCLUSION}

Both hyaluronic acid and corticosteroids were effective to reduce the symptoms of osteoarthritis knee in our target population, but intraarticular steroids emerged as the better option from the two in terms of efficacy for knee osteoarthritis.

\section{CONFLICT OF INTEREST}

This study has no conflict of interest to be declared by any author.

\section{REFERENCES}

1. Elliott AM, Smith BH, Penny KI, Smith WC, Chambers WA. The epidemiology of chronic pain in the community. Lancet 1999; 354(9186): 1248-52.

2. Sen R, Hurley JA. Osteoarthritis. In: StatPearls. Treasure Island (FL): 2020 [Internet]. Available from: https://www.ncbi.nlm.nih. gov/books /NBK482326/.

3. Heidari B. Knee osteoarthritis prevalence, risk factors, pathogenesis and features: Part I. Caspian J Intern Med 2011; 2(2): 205-12.

4. Hsu H, Siwiec RM. Knee Osteoarthritis. [Updated 2019 Sep 29]. In: StatPearls. Treasure Island (FL): StatPearls Publishing; 2020 Jan. 2019 [Internet] Available from: https://www.ncbi.nlm. nih. gov/books/NBK507884/.

5. Bannuru RR, Osani MC, Vaysbrot EE, Arden NK, Bennell K, Bierma-Zeinstra SMA, et al. OARSI guidelines for the non-sur- gical management of knee, hip, and polyarticular osteoarthritis. Osteoarth Cartil 2019; 27(11): 1578-89.

6. Mora JC, Przkora R, Cruz-Almeida Y. Knee osteoarthritis: pathophysiology and current treatment modalities. J Pain Res 2018; 11(1): 2189-96.

7. Leopold SS, Redd BB, Warme WJ, Wehrle PA, Pettis PD, Shott S. Corticosteroid compared with hyaluronic acid injections for the treatment of osteoarthritis of the knee. A prospective, randomized trial. J Bone Joint Surg Am 2003; 85(7): 1197-1203.

8. Tammachote N, Kanitnate S, Yakumpor T. Intra-articular, singleshot hylan G-F 20 hyaluronic acid injection compared with corticosteroid in knee osteoarthritis: a double-blind, randomized controlled trial. J Bone Joint Surg Am 2016; 98(11): 885-92.

9. Smith C, Patel R, Vannabouathong C, Sales B, Rabinovich A, McCormack R, et al. Combined intra-articular injection of corticosteroid and hyaluronic acid reduces pain compared to hyaluronic acid alone in the treatment of knee osteoarthritis. Knee Surg Sports Traumatol Arthrosc 2019; 27(6): 1974-83.

10. Ayaz SB, Rathore FA, Ahmad K, Matee S. The use of complementary health approaches among patients with knee osteoarthritis in Pakistan: A hospital based survey. Egypt Rheumatol 2016; 38(2): 111-16.

11. Sinusas K. Osteoarthritis: diagnosis and treatment [published correction appears in Am Fam Physician. Am Fam Phys 2012; 85(1): 49-56.

12. Lussier A, Cividino AA, McFarlane CA, Olszynski WP, Potashner WJ, De Médicis R. Viscosupplementation with hylan for the treatment of osteoarthritis: findings from clinical practice in Canada. J Rheumatol 1996; 23(9): 1579-85.

13. Tian $\mathrm{K}$, Cheng $\mathrm{H}$, Zhang J, Chen K. Intra-articular injection of methylprednisolone for reducing pain in knee osteoarthritis: A systematic review and meta-analysis [retracted in: Medicine (Baltimore). Med (Baltimore) 2018; 97(15): e0240-44.

14. Bowman S, Awad ME, Hamrick MW, Hunter M, Fulzele S. Recent advances in hyaluronic acid based therapy for osteoarthritis. Clin Transl Med 2018; 7(1): 6-8.

15. Mc Connell S, Kolopack P, Davis AM. The Western Ontario and McMaster Universities Osteoarthritis Index (WOMAC): a review of its utility and measurement properties. Arthritis Rheum 2001; 45(5): 453-61.

16. Abedi M, Kamkar P, Afshari M, Mirkazemi M. Comparison of the effectiveness of intra-articular injections of hyaluronic acid and corticosteroid in the treatment of patients with knee osteoarthritis symptoms. Ortho Rheum Open Access 2017; 7(1): 555704.

17. Ran J, Yang X, Ren Z, Wang J, Dong H. Comparison of intra-articular hyaluronic acid and methylprednisolone for pain management in knee osteoarthritis: A meta-analysis of randomized controlled trials. Int J Surg 2018; 53(3): 103-10.

18. Yaftali NA, Weber K. Corticosteroids and hyaluronic acid injections. Clin Sports Med 2019; 38(1): 1-15. 